\title{
The Effect of Acetylcholine and Potassium on Repolarization of the Heart *
}

\author{
Charles Fisch, Suzanne B. Knoebel, and Harvey Feigenbaum $\dagger$ \\ (From the Division of Cardiology, Department of Medicine, and the Heart Research Center, \\ Indiana University School of Medicine, and the Krannert Heart Research Institute, \\ Marion County General Hospital, Indianapolis, Ind.)
}

Acetylcholine has been shown to have an effect on the action potentials of mammalian atrial muscle, the sinoatrial and the atrioventricular nodes, and on the action potential of frog ventricles $(1-4)$. On the other hand, the action potential of mammalian ventricle has been found to be highly resistant to acetylcholine. Only very slight changes were noted in the presence of enormous concentrations of the drug (4-6).

The purpose of this communication is to present electrocardiographic evidence indicating $a$ ) that acetylcholine exerts a consistent effect on repolarization of the ventricles in the intact dog and that this effect is independent of the heart rate, ventricular arrhythmias, and atrioventricular (AV) or intraventricular conduction delays, and b) that the effect of acetylcholine on repolarization is augmented by increasing the level of plasma potassium $(\mathrm{K})$.

\section{Methods}

Eleven experiments were performed with seven mongrel dogs weighing 10 to $14 \mathrm{~kg}$. The animals were anesthetized with either pentobarbital, $30 \mathrm{mg}$ per $\mathrm{kg}$ iv, or a combination of morphine sulfate, $2.5 \mathrm{mg}$ per $\mathrm{kg}$ im, followed by pentobarbital, $15 \mathrm{mg}$ per $\mathrm{kg}$ iv. Ventilation was maintained through the use of a Harvard respirator. A bilateral cervical vagotomy was performed, and an arterial catheter was placed just above the aortic valves. Blood pressure was continuously recorded through a Cournand needle in the femoral artery. The entire experiment was monitored with an oscilloscope, and permanent records were obtained with a direct-

\footnotetext{
* Submitted for publication January 10, 1964; accepted May 15, 1964.

Supported by the Herman C. Krannert Fund, the Indiana Heart Association, Indiana State Board of Health, in part by U. S. Public Health Service training grant 5363, and in part with facilities provided by cardiovascular clinical research grant $\mathrm{H}-6308$ from the National Heart Institute, U. S. Public Health Service.

$\dagger$ Work done as trainee of the National Heart Institute.
}

writing electrocardiograph using standard lead II connections. Frequent determinations of arterial plasma $\mathrm{K}$ were made with a Beckman flame photometer.

Increasing amounts of acetylcholine were injected through the catheter for 15 seconds until a total amount was reached that consistently induced second or third degree AV block. With an electric interval timer this amount of acetylcholine was then given every $2 \mathrm{~min}$ utes without interruption throughout the experiment. Four to eight injections of this dose were made in normokalemic dogs, and the effect on the duration of $R-R, Q-T$ intervals and the amplitude of the $T$ waves was measured before the appearance of $\mathrm{AV}$ block and after AV block appeared. ST-T segment position and configuration were also observed. The plasma $\mathrm{K}$ levels were then elevated by the infusion of a buffered isotonic (155 $\mathrm{mEq}$ per $\mathrm{L}$ ) solution of $\mathrm{K}$ phosphate in distilled water administered at a rate of 0.5 to $1.0 \mathrm{mEq}$ per minute through a femoral vein catheter. The effect on the ECG was evaluated as above with acetylcholine injection in these hyperkalemic animals. As a control study, identical experiments were carried out with the substitution of isotonic buffered sodium phosphate for the $\mathrm{K}$ solution.

\section{Results}

The amount of acetylcholine that was administered averaged $0.295 \mathrm{mg}$ per 15 -second injection, with a range of 0.096 to 0.955 from experiment to experiment. As pointed out in an earlier communication, this variation from experiment to experiment may have been due, among other factors, to the placement of the catheter in relation to the coronary ostia resulting in unequal perfusion of the two coronary arteries $(7,8)$.

In 8 of 11 experiments, when the plasma $K$ was normal, acetylcholine had a definite effect on the amplitude of the T wave of the ECG within 5 to 10 seconds after the start of injection and before the appearance of AV block $(p<0.01)$. In the remaining three experiments $(274,275,276-1)$, before appearance of $\mathrm{AV}$ block no change in height of $\mathrm{T}$ wave was measurable, but a change 


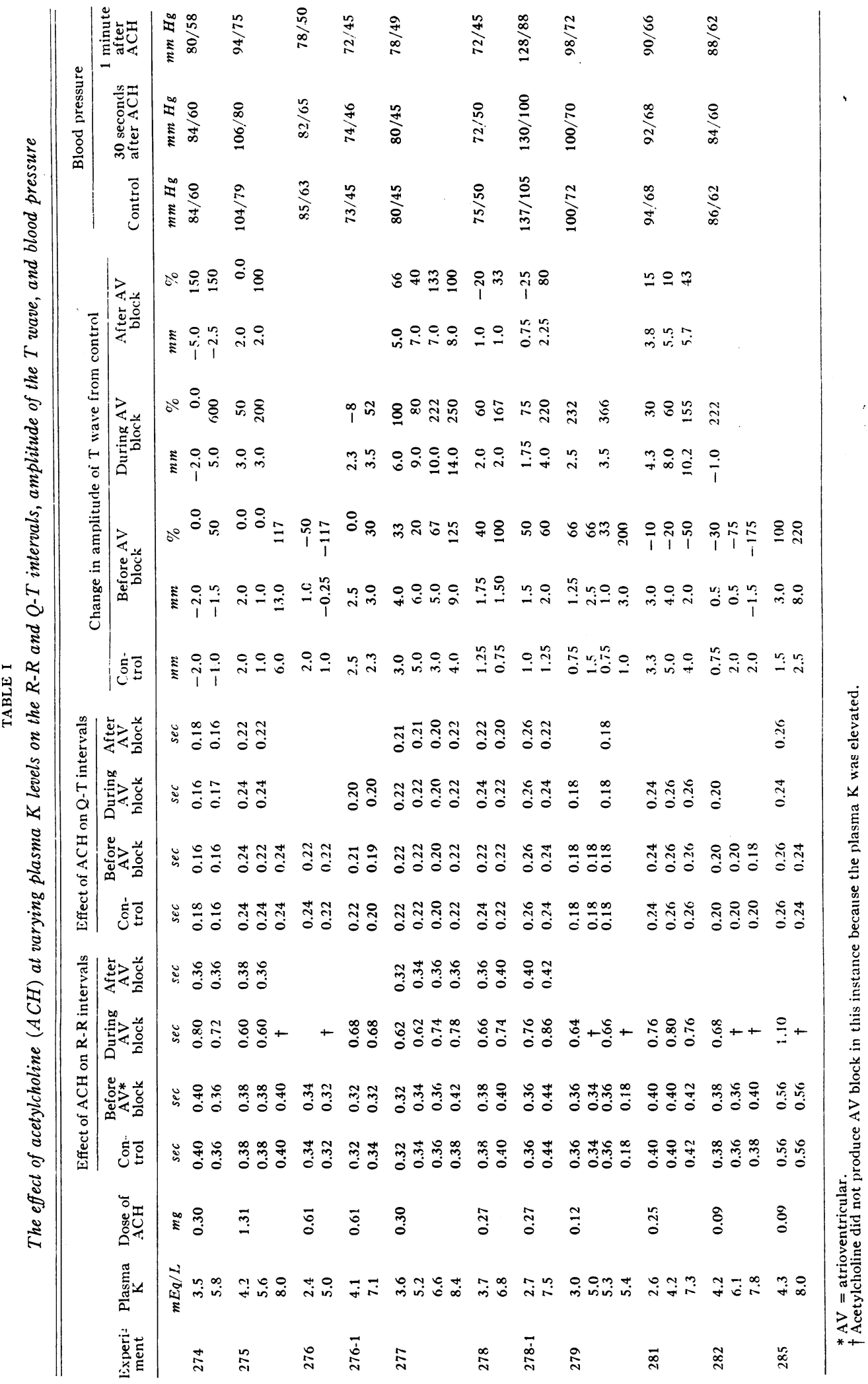


TABLE II

Change in amplitude of $T$ wave due to acetylcholine

\begin{tabular}{|c|c|c|c|c|c|c|c|c|c|c|c|c|c|c|}
\hline \multirow{4}{*}{$\begin{array}{l}\text { Experi- } \\
\text { ment }\end{array}$} & \multicolumn{6}{|c|}{ Normal plasma $K$ (A) } & \multicolumn{6}{|c|}{ Elevated plasma $\mathbf{K}(\mathrm{B})^{*}$} & \multicolumn{2}{|c|}{$\begin{array}{c}\text { Difference between } \\
\mathbf{A} \text { and } \mathbf{B}\end{array}$} \\
\hline & \multirow{3}{*}{$\frac{\mathrm{K}}{m E q / L}$} & \multicolumn{3}{|c|}{ Before AV block } & \multirow{2}{*}{\multicolumn{2}{|c|}{$\frac{\text { During AV block }}{\text { Change }}$}} & \multirow{3}{*}{$\frac{\mathrm{K}}{m E q / L}$} & \multicolumn{3}{|c|}{ Before AV block } & \multirow{2}{*}{\multicolumn{2}{|c|}{$\frac{\text { During AV block }}{\text { Change }}$}} & \multirow{3}{*}{$\begin{array}{c}\begin{array}{c}\text { Before } \\
\text { AV } \\
\text { block }\end{array} \\
\%\end{array}$} & \multirow{3}{*}{$\begin{array}{c}\begin{array}{c}\text { During } \\
\text { AV } \\
\text { block }\end{array} \\
\%\end{array}$} \\
\hline & & \multirow{2}{*}{$\frac{\text { Control }}{m m}$} & \multicolumn{2}{|c|}{ Change } & & & & \multirow{2}{*}{ Control } & \multicolumn{2}{|c|}{ Change } & & & & \\
\hline & & & $m m$ & $\%$ & $m m$ & $\%$ & & & $m m$ & $\%$ & $m m$ & $\%$ & & \\
\hline 274 & 3.5 & 2.0 & 0.0 & $\mathbf{0}$ & 0.0 & 0 & 5.8 & 1.0 & 0.5 & 50 & 6.0 & 600 & 50 & 600 \\
\hline 275 & 4.2 & 2.0 & 0.0 & 0 & 1.0 & 50 & 5.6 & 1.0 & 0.0 & 0 & 2.0 & 200 & $\mathbf{0}$ & 150 \\
\hline 276 & 2.4 & 2.0 & 1.0 & 50 & & & 5.0 & 1.5 & 1.25 & 117 & & & 67 & \\
\hline 276-1 & 4.1 & 2.5 & 0.0 & $\mathbf{0}$ & 0.2 & 8 & 7.1 & 2.3 & 0.7 & 30 & 1.2 & 52 & 30 & 44 \\
\hline 277 & 3.6 & 3.0 & 1.0 & 33 & 3.0 & 100 & 8.4 & 4.0 & 5.0 & 125 & 10.0 & 250 & 92 & 150 \\
\hline 278 & 3.7 & 1.25 & 0.5 & 40 & 0.75 & 60 & 6.8 & 0.75 & 0.75 & 100 & 1.25 & 167 & 60 & 107 \\
\hline 278-1 & 2.7 & 1.0 & 0.5 & 50 & 0.75 & 75 & 7.5 & 1.25 & 0.75 & 60 & 2.75 & 220 & 10 & 145 \\
\hline 279 & 3.0 & 0.75 & 0.5 & 66 & & & 5.4 & 1.0 & 2.0 & 200 & & & 134 & \\
\hline 281 & 2.6 & 3.3 & 0.3 & 10 & 1.0 & 30 & 7.3 & 4.0 & 2.0 & 50 & 6.2 & 155 & 40 & 125 \\
\hline 282 & 4.2 & 0.75 & 0.25 & 33 & & & 7.8 & 2.0 & 3.5 & 175 & & & 142 & \\
\hline 285 & 4.3 & 1.5 & 1.5 & 100 & & & 8.0 & 2.5 & 5.5 & 220 & & & 120 & \\
\hline Mean & & 1.82 & 0.5 & 34.5 & 0.96 & 46 & & 1.94 & 2.40 & 102 & 4.2 & 235 & 68 & 189 \\
\hline SD & & \pm .87 & \pm 0.49 & \pm 32.0 & \pm 0.98 & \pm 36 & & \pm 1.17 & \pm 2.00 & \pm 73 & \pm 3.3 & \pm 173 & \pm 49 & \pm 195 \\
\hline $\mathbf{p}$ & & & $<0.01$ & & & & & & $<0.001$ & & & & $<0.001$ & $<0.05$ \\
\hline
\end{tabular}

* Highest plasma $\mathrm{K}$ at which acetylcholine induced $\mathrm{AV}$ block.
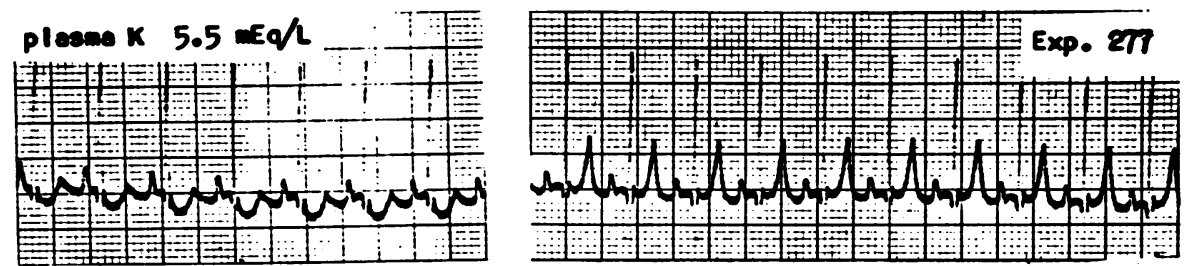
K $3.4 \mathrm{mEd} / \mathrm{L}$ 11. o :

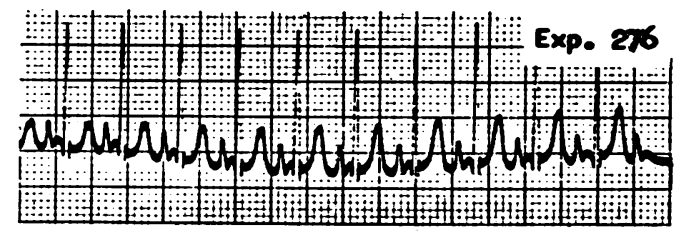

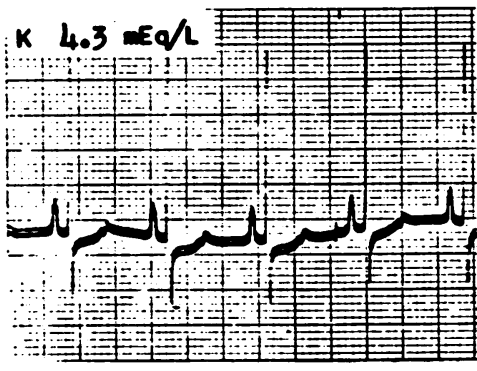

A

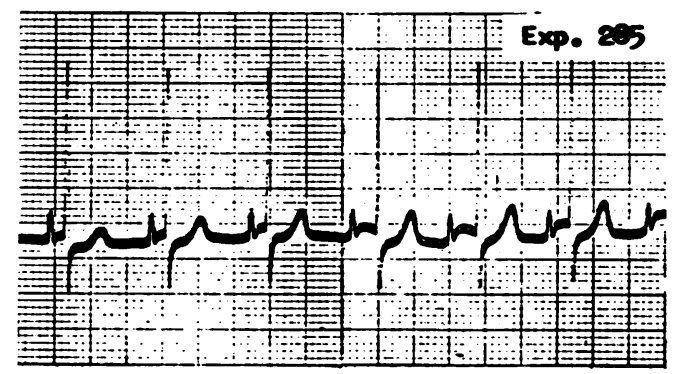

8

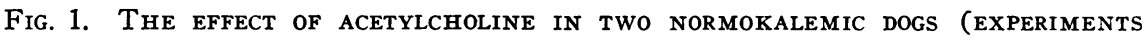
276, 285) AND ONE With AN Elevated Plasma K (EXPERIMent 277). The T-wave changes are independent of the heart rate or alteration of the $Q R S$ complex. The strips in columns $\mathrm{A}$ and $\mathrm{B}$ were obtained before and during injection of acetylcholine. The dose of the drug was $0.30,0.61$, and $0.09 \mathrm{mg}$ in experiments 277,276 , and 285 , respectively. In experiments 276 and 285, in addition to $\mathrm{T}$-wave changes, the $\mathrm{P}$ waves became diphasic, the $\mathrm{Ta}$ segment elevated, and the $\mathrm{P}-\mathrm{R}$ interval prolonged. 
in configuration was noted. In all 11 experiments T-wave amplitude was altered by acetylcholine after plasma $\mathrm{K}$ was elevated $(\mathrm{p}<0.001)$. The percentage of change in $\mathrm{T}$-wave amplitude produced by acetylcholine was greater in all cases when the animals were hyperkalemic than that demonstrated in normokalemic dogs $(p<0.001)$. The alteration in $T$ wave was independent of blood pressure and the $R-R$ interval. There was no significant change in the $Q-T$ interval.

In seven experiments $\mathrm{AV}$ block was produced by acetylcholine at both normal and elevated plasma $\mathrm{K}$ levels. The acetylcholine effect on T-wave amplitude during AV block was also consistently augmented by increased plasma $\mathrm{K}$ levels $(\mathrm{p}<0.05)$.

In three experiments acetylcholine injection resulted in a shift of the ST segments. These changes were accentuated by elevation of plasma $\mathrm{K}$.

The effect of acetylcholine at different $\mathrm{K}$ levels on the heart rate, amplitude of the $\mathrm{T}$ waves, $\mathrm{Q}-\mathrm{T}$ interval, and blood pressure for all 11 experiments is presented in Tables I and II.

Figure 1 (experiments $277,276,285$ ) is an example of the effect of acetylcholine on the $\mathrm{T}$ wave in two normokalemic animals $(276,285)$ and in one in which the plasma $\mathrm{K}$ was elevated (277). The strips on the left show the ECG before injection of acetylcholine. The ones on the right were recorded during the injection of acetylcholine and immediately before the appearance of AV block. An increase in amplitude of $\mathrm{T}$ waves is noted in all three strips. In addition a prolongation of $\mathrm{P}-\mathrm{R}$ interval is evident. In experiments 266 and 285 the $\mathrm{P}$ wave became diphasic and the P-Ta segment elevated. No change in shape or duration of $\mathrm{QRS}$ nor any measurable change in the duration of the QT interval was observed. This figure also demonstrates that the effect of acetylcholine on the $T$ wave is independent of the heart rate.

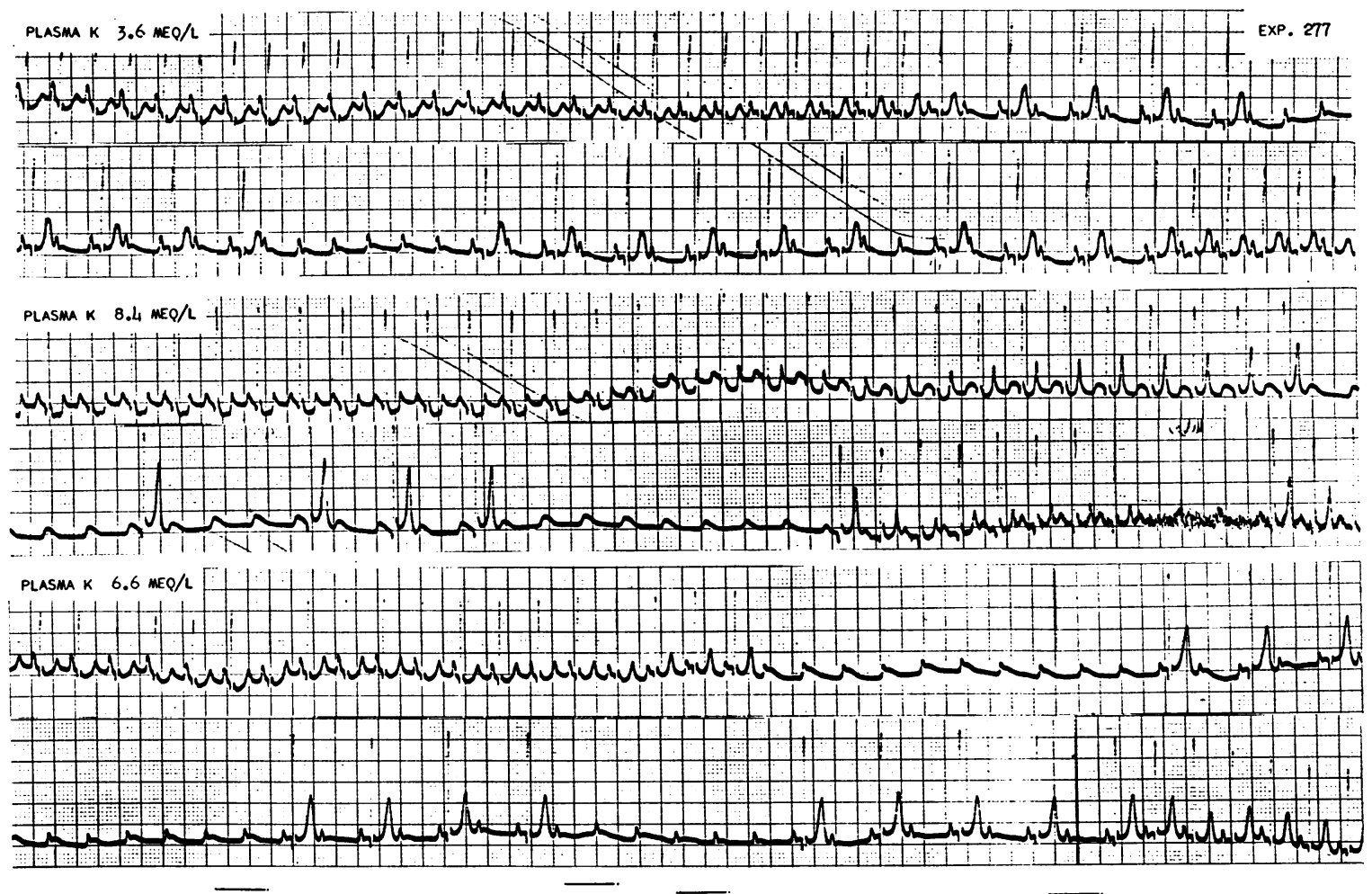

Fig. 2. Continuous tracings of three separate injections of 0.30 Mg of acetylcholine at difFERENT Plas ma LEVELS OF K. The beginning of each strip signifies the onset of injection. Prompt alteration of the $T$ wave is evident, and this alteration is exaggerated by elevating the plasma $\mathrm{K}$. In addition, the effect of acetylcholine on $\mathrm{P}$ and $\mathrm{Ta}$ is augmented by raising the plasma $\mathrm{K}$. 


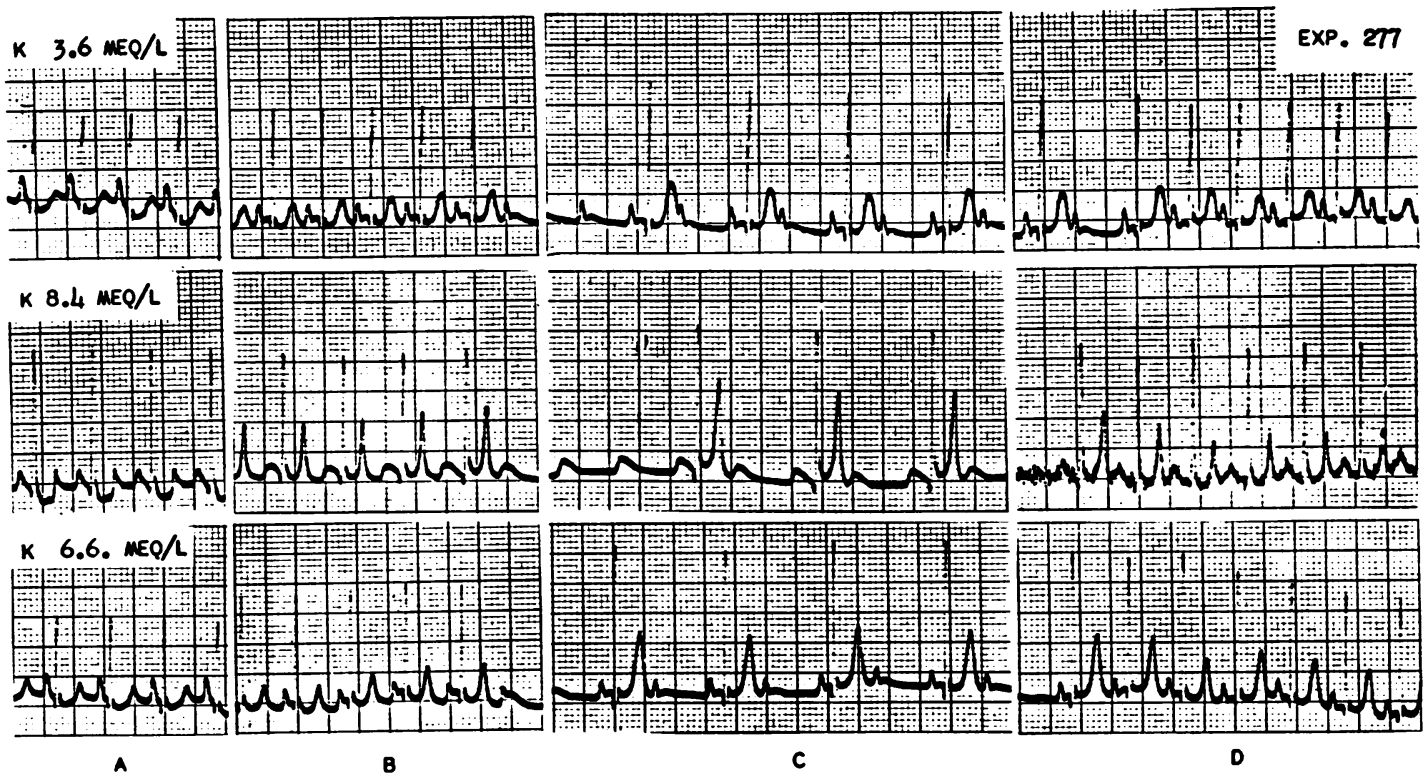

Fig. 3. More detailed Representation of the Changes described in Figlre 2. Rows A, B, C, and D are representative of tracings recorded at the start of acetylcholine injection, just before appearance of AV block, during the AV block, and immediately after disappearance of the block.
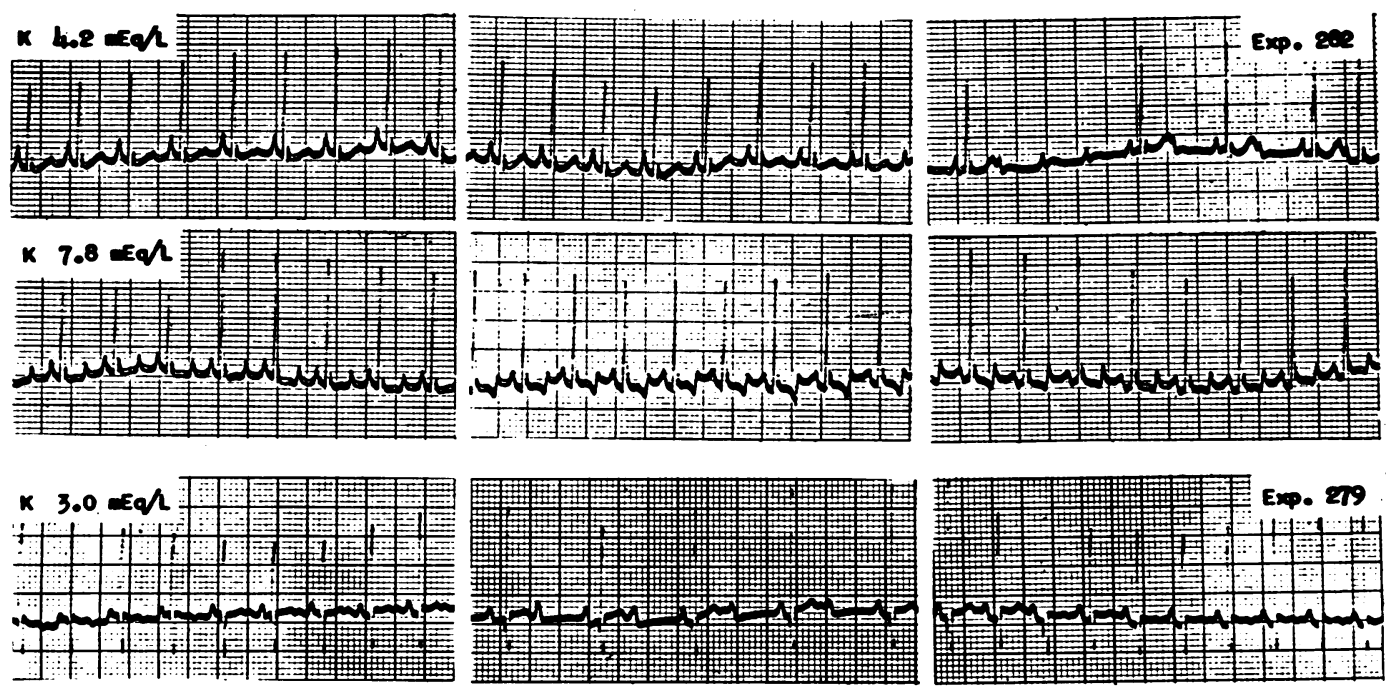

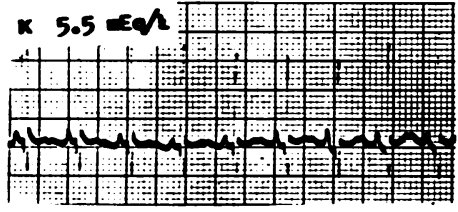

A

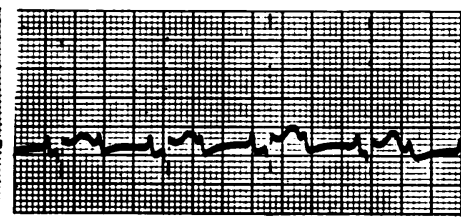

B

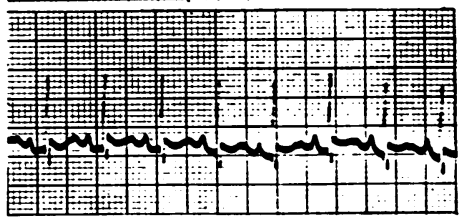

C

Fig. 4. The accentuation of T-Wave Negativity (experiment 282) and elevation of S-T Seg-

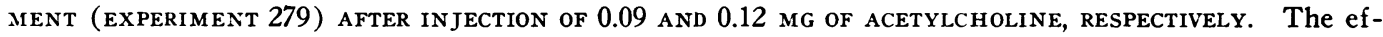
fect of acetylcholine on the $\mathrm{T}$ wave in experiment 282 was accentuated by raising the plasma $\mathrm{K}$ to 7.8 $\mathrm{mEq}$ per L. Similarly the shift of S-T segment in experiment 279 was augmented by elevating the plasma $\mathrm{K}$ to $5.5 \mathrm{mEq}$ per $\mathrm{L}$. 
Figure 2 (experiment 277) shows continuous recordings during three separate injections of acetylcholine. The injections were made at plasma $\mathrm{K}$ of $3.6,8.4$, and $6.6 \mathrm{mEq}$ per $\mathrm{L}$, respectively. In addition to the previously described effect of acetylcholine when the plasma $K$ is normal (top tracing), the augmentation of the acetylcholine effect on the $T$ wave at an elevated plasma $K$ level is demonstrated. The accentuation of the $\mathrm{T}$-wave amplitude is evident before and after appearance of acetylcholine-induced AV block. The heart rate during $\mathrm{AV}$ block was the same in all three injections. The most marked $\mathrm{T}$-wave change is evident at a plasma $\mathrm{K}$ level of $8.4 \mathrm{mEq}$ per $\mathrm{L}$ with lesser alterations at a plasma $\mathrm{K}$ of $6.6 \mathrm{mEq}$ per $\mathrm{L}$. The alteration of $\mathrm{P}$ and $\mathrm{Ta}$ segment also is most pronounced at the higher plasma $\mathrm{K}$ level. The changes described in Figure 2 are presented in greater detail in Figure 3, where rows A, B, C, and $D$ are representative sections of tracings recorded before acetylcholine injection, just before the appearance of AV block, during the AV block, and immediately after disappearance of the block.

In Figure 4 the strips shown in rows $A, B$, and $C$ were recorded at the start, at the end, and 10 seconds after infusion was stopped. Experiment 282 shows that with elevation of plasma $\mathrm{K}$ to 7.8 $\mathrm{mEq}$ per $\mathrm{L}$ acetylcholine accentuates the biphasic nature of the $T$ wave (row B). Experiment 279 is an example of an observation made in 3 of the 11 experiments in which acetylcholine, in addition to increasing the height of the $\mathrm{T}$ wave, shifted $\mathrm{S}-\mathrm{T}$ segment. This elevation was most striking when the plasma $\mathrm{K}$ was raised.

\section{Discussion}

The data show that acetylcholine when injected just above the aortic valves of the normokalemic $\operatorname{dog}$ had a measurable effect on the amplitude of the $\mathrm{T}$ wave of the surface ECG in 8 of 11 experiments, and in 3 the configuration of the $T$ wave changed. The measurement of the T-wave amplitude during infusion of acetylcholine is at times difficult because of the appearance of Ta segment, a shift of $\mathrm{J}$ point, and alteration in contour and position of ST segment. In each experiment the effect of acetylcholine on the $T$ wave was augmented by increasing the plasma $\mathrm{K}$ level. $\mathrm{T}$-wave changes may be due either to altered conduction velocity or to primary change in the duration of repolarization. In our experiments the configuration and duration of the QRS remained unchanged, and for this reason the alteration in height and configuration of the $\mathrm{T}$ wave is primary and indicative of accelerated repolarization. The variation in magnitude of $T$-wave change from experiment to experiment may be due to an uneven effect of acetylcholine on repolarization of the ventricle.

The failure of the QT interval to change in our experiments might result from uneven perfusion of the myocardium or, if perfusion were uniform, from an inhomogeneous effect on repolarization $(9,10)$ of the ventricle. The failure to register change of the Q-T interval, on the other hand, may be due to lack of sufficient sensitivity and fine resolution of the recording instrument. It should be noted, however, that the $Q-T$ interval did not increase despite reduction of the heart rate due to AV block.

Although the surface ECG does not give precise information as to the electrical behavior of the cell, it is the differential quotient of the monophasic action potentials of the cardiac fibers (1113) ; thus, our results might be assumed to indicate an effect of acetylcholine on the mammalian ventricle. As suggested by Hecht (13), alteration of R-T junction and RS-T segment may be related to change in the first phase of recovery and alteration of the $T$ wave to modification of the duration of the slope of the final recovery process (phase 3).

The clear demonstration of the effect of acetylcholine on repolarization in our experiments is in contrast to observations of previous workers. The discrepancy can perhaps be explained by the technique of intracoronary injection in the intact animal. The possibility must also be considered that, in the intact animal, liberation of other effector substances such as catecholamines from the stores within the heart itself contributed to ST-T changes observed in our experiments (14). It may also be that for an acetylcholine effect on the action potentials of ventricle to become manifest, the proper $\mathrm{K}$ environment needs to be present. If acetylcholine affects the repolarization phase of the action potential by increasing $\mathrm{K}$ permeability, the importance of sufficient $\mathrm{K}$ is implied (15-19). 
A discussion of the changes noted in atrial repolarization in our experiments is not pertinent; they may in part be due to change in atrial conductivity as indicated by alteration in appearance and duration of the $\mathrm{P}$ wave.

\section{Summary}

Acetylcholine has been shown to alter the repolarization of the ventricles in the intact dog. This effect is augmented by raising the plasma level of potassium.

\section{References}

1. Burn, J. H., E. M. V. Williams, and J. M. Walker. The effects of acetylcholine in the heart-lung preparation including the production of auricular fibrillation. J. Physiol. (Lond.) 1955, 128, 277.

2. Loomis, T. A., and S. Krop. Auricular fibrillation induced and maintained in animals by acetylcholine or vagal stimulation. Circulat. Res. 1955, 3, 390.

3. Cranefield, P. F., B. F. Hoffman, and A. P. de Carvalho. Effects of acetylcholine on single fibers of the atrioventricular node. Circulat. Res. 1959, $7,19$.

4. Hoffman, B. F., and P. F. Cranefield. Electrophysiology of the Heart. New York, McGraw-Hill, 1960, pp. 56, 86, 277.

5. Rothschuh, K. E. Electrophysiologie des Herzens. Darstelling, Kritie, Probleme. Darmstadt, Verlag Dr. O. Steinkopff, 1952.

6. Hoffman, B. F., and E. E. Suckling. Cardiac cellular potentials: effect of vagal stimulation and acetylcholine. Amer. J. Physiol. 1953, 173, 312.

7. Fisch, C., H. Feigenbaum, and J. A. Bowers. The inhibition of acetylcholine-induced atrioventricular block by potassium. J. clin. Invest. 1963, 42, 563.
8. James, T. N. Anatomy of the Coronary Arteries, New York, Paul B. Hoeber, 1961, p. 162.

9. Schaefer, H., and H. G. Haas. Handbook of Physiology. Circulation. Baltimore, Williams and Wilkins, 1962, p. 382.

10. Han, J., and G. K. Moe. Nonuniform recovery of excitability of ventricular muscle. Circulat. Res. 1964, 14, 44.

11. Eyring, H., and R. Parlin. Some molecular aspects of heart behavior. Ann. N. Y. Acad. Sci. 1957, $65,679$.

12. Hecht, H. H. Some observations on theories concerning the electrical behavior of heart muscle. Amer. J. Med. 1961, 30, 720.

13. Hecht, H. H. Normal and abnormal transmembrane potentials of the spontaneously beating heart. Ann. N. Y. Acad. Sci. 1957, 65, 700.

14. Hoffmann, F., E. Hoffmann, S. Middleton, and J. Talesnik. The stimulating effect of acetylcholine on the mammalian heart and the liberation of an epinephrine-like substance by the isolated heart. Amer. J. Physiol. 1945, 144, 189.

15. Holland, W. C., C. E. Dunn, and M. E. Greig. Studies on permeability, VIII. Role of acetylcholine metabolism in the genesis of the electrocardiogram. Amer. J. Physiol. 1952, 170, 339.

16. Hodgkin, A. L., and R. D. Keynes. The potassium permeability of a giant nerve fibre. J. Physiol. (Lond.) 1955, 128, 61.

17. Hodgkin, A. L., and P. Horowicz. The influence of potassium and chloride ions on the membrane potential of single muscle fibres. J. Physiol. (Lond.) 1959, 148, 127.

18. Hutler, O. F., and D. Noble. Rectifying properties of heart muscle. Nature (Lond.) 1960, 188, 495.

19. Harris, E. J., and O. F. Hutler. The action of acetylcholine on the movements of potassium ions in the sinus venosus of the heart. J. Physiol. (Lond.) 1956, 133, 58. 